Nadir B. Aghayev', Amina N. Aghazade

DOI: 10.25045/jpit.v08.i1.04

${ }^{1}$ National Aviation Academy, Baku, Azerbaijan

${ }^{2}$ Institute of Information Technology of ANAS, Baku, Azerbaijan

${ }^{1}$ nadir_avia@yahoo.com, ${ }^{2}$ emina635@gmail.com

\title{
EVALUATION OF THE VIRTUAL LEARNING SYSTEMS USAGE
}

The article tasks with developing a model assessing the quality of use of information resources usage in virtual learning systems, and proposes a method for the problem solution. The model can be used to assess the rating of various information resources, and for the preliminary estimation of test papers in distance and traditional education.

Keywords: virtual environment, virtual learning environment, knowledge assessment, discrete random time series, penalty point.

\section{Introduction}

Recently, the rapid development of information technology (IT) has caused fundamental changes in all spheres of human activity, as a result of which a qualitatively new atmosphere - a new concept of a virtual environment has established in the human-nature-energy-information interaction [1-3].

Virtual environment:

1) enables to solve the problems arising (geographic space inaccessibility, time, financial, administrative and other problems) when acquiring the knowledge;

2) delivers large volumes of digital information resources to any user through the global network;

3) enables to respond to any query referring to the information available in different (public research, corporate, personal, etc.) sources or to get related information;

4) is available to each user without requiring specific knowledge (both technical and software point of view).

Virtual environment is widely used in secondary and high schools for the acquisition of knowledge as a new form of interaction with the environment. This is obvious especially in the distance education, which is considered as a new form of study during the last few years. Thousands of student are now using this virtual learning system offered by most universities $[4,5]$.

These systems have been established mainly based on traditional forms of education through the use of IT resources. Unlike the traditional forms, the seminars, lectures, and course works are prepared by citing to the information resources more quickly. These systems also use tests and inspection tasks to monitor and evaluate the success of the learners as in the traditional education [4-7]. However, none of these systems include the main goal of the modern education system, which is the learning process aimed at developing the learners' creativity and understanding characteristics $[8,9]$. As the problem solution, we can note the following trends:

1) organizing the regular contacts between the information sources (web site administrators) and the students (who want to acquire knowledge) in these systems. The regular bilateral contacts can manage and evaluate the activities of the learners in the learning process.

2) providing the knowledge system dynamically adaptable to the capabilities, level and requirements of each student by specifically approaching to each of them using artificial intelligence technologies.

The evaluation of these teaching systems should be implemented by taking into account the characteristics of each of these aspects. In this article, we present the method for the evaluation of the learners using the information sources based on the statistical data by organizing the regular contacts between the information sources and the students. 


\section{Problem statement}

Thus, summarizing all the above mentioned, the problem can be formed as follows:

If the user freely uses the complex software system (information sources), he/she requires to develop the model to evaluate the quality of the system usage.

The term "Free use" means that the user can use software system anytime and period without any limitation.

\section{Problem solution method}

$n$ - denotes the number of modules available in the system, and $m_{j}$ - the number of submodules available in each of the $j$-th module. In this case, the number of all modules in the system will be as follows:

$$
N=\sum_{j=1}^{n} m_{j}
$$

The user $n_{j i}$ times accesses the submodule $(j=1, n) i$ - ci $\left(i=1, m_{j}\right)$ of each $j$-th module. Each of these accesses continues $t_{j i}$ period of time. In general, $n_{j i}$ and $t_{j i}$ are random figures. The frequency of the access to each $j$-th sub=module is calculated by the following formula:

$$
h_{j}=\frac{\sum_{i=1}^{m_{j}} n_{j i}}{\sum_{i=1}^{m} t_{j i}}
$$

We denote minimum and maximum duration at each sub-module, that the user accesses as $t_{j i}^{\max }$ and $t_{j i}^{\mathrm{min}}$, respectively, depending on the volume and complexity rates of the knowledge required to obtain the proficiency from each sub-module. Of course, in this case, the condition $t_{j i}^{\min } \leq t_{j i} \leq t_{j i}^{\max }$ shall be provided for each user. These durations shall be determined by an expert evaluation.

Thus, we obtain the discrete random time series $t_{j i}$ of durations for each user accessing the sub-modules. Considering that the series is distributed by the normal rule (this hypothesis is derived from the condition of invincibility interdependent elements of the sequence), let's build the reliability interval for each $j$-th $(j=1, n)$ module:

$$
\left(\bar{t}_{j}-\frac{\sigma_{j}}{\sqrt{m}_{j}} t_{\alpha, m_{j}-1}, \quad \bar{t}_{j}+\frac{\sigma_{j}}{\sqrt{m}_{j}} t_{\alpha, m_{j}-1}\right), \quad j=1, \ldots, n .
$$

Here:

$\bar{t}_{j}$ - denotes the mean duration at the $j$-th module :

$$
\overline{t_{j i}}=\frac{1}{m_{j}} \sum_{i=1}^{m_{j}} t_{j i}
$$

$\sigma_{j}$-denotes the dispersion of the duration at the module:

$$
\sigma_{j}=\sqrt{\frac{1}{m_{j}-1} \sum_{i=1}^{m_{j}}\left(t_{j i}-\overline{t_{j}}\right)^{2}}
$$

$t_{\alpha, m_{j}-1}$ - the reliability rate $p=1-\alpha$ (usually $\mathrm{p}=0.95$, in other words, $95 \%$ reliability rate) the critical value of the freedom rate $m_{j}-1$ and the distribution 1 , which is found with the special tables [10].

The boundary values of the interval determined by the formula (3) can be considered as the critical minimum and maximum duration at the sub-module.

The characteristics (2) - (5) of the random time series consisting of the durations used for the information source by the user could play a key role in assessing the rate of knowledge 
acquisition. Since the module is accessed to acquire knowledge, we should add previously available and stable value $b_{j i}$ to the knowledge of the user. This value should be called base value. The initial value of the knowledge rate equals to 0 . Let's review the following conditional cases to assess the knowledge rate of the user:

- the user's duration at the module is normal;

- the user's duration at the module is less than the norm;

- the user's duration at the module exceeds the norm;

- the user often deliberately accesses the module;

- the user attempts to violate system.

In the first case, if the user stays at the submodule within the interval (3), then the base value is added to the balance of his/her values. In other cases, either the balance of the user does not change or the system "punishes" him/her depending on the results of the control process in accordance with the following circumstances:

- if the duration of stay at each submodule is less than the critical minimum duration $t_{j i} \leq t_{j i}^{\text {critical min }}$ ), then the penalty points are deducted from his/her balance of values for each click of the user, respectively. The penalty points cji- is determined in advance and has a fixed value. Critical minimal duration is defined as the minimum duration of stay at the sub-module by the experts using the method of speedy reading, or as a $t_{j i}^{\text {critical }}=t_{j i}^{\min }-3 \sigma_{j}$;

- if the duration of stay at the module is less than the norm and provides the condition $t_{j i}^{\text {critical }}<t_{j i}<t_{j i}^{\min }$, and if the number of cases does not exceed $20 \%$ of the access to the module [11], then the user's behavior is considered to be normal. Otherwise, the penalty points are deducted from the user's balance. In this case, leaving the sub-module is considered to be random.

- if the duration of stay at each sub=module is longer than the critical maximum duration, that is $t_{j i} \geq t_{j i}^{\text {critical max }}$ or if they are accessed only in few cases, in other words, the frequency of accesses provides the condition

$$
h_{j} \geq \frac{\sum_{i=1}^{m_{j}} n_{j i}}{\sum_{i=1}^{m_{j}} t_{j i}^{\max }}=h_{j}^{\max }
$$

the process stops automatically. In this case, we decided that the user is too tired or it is a temporary interruption. Hence, in this case, no penalty points are appointed to the user. As in the previous cases, the critical maximum duration of stay at the sub-module is defined by the experts, or as $t_{j i}^{\text {critical max }}=t_{j i}^{\max }+3 \sigma_{j}$;

- if the duration of stay at each sub-module is longer than the norm and provides the condition $t_{j i}^{\max } \leq t_{j i}<t_{j i}^{\text {criticalmax }}$, and if the number of these cases does not exceed $20 \%$ of the accesses to the module, the user's balance remains unchanged. Otherwise, it is considered as an attempt to mislead the system and the penalty points are deducted from the balance.

- If the modules are deliberately often accessed, in other words, the frequency of accesses provides the condition

$$
h_{j} \leq \frac{\sum_{i=1}^{m_{j}} n_{j i}}{\sum_{i=1}^{m_{j}} t_{j i}^{\min }}=h_{j}^{\mathrm{min}}
$$

which is regarded as an attempt to mislead the system and the penalty points are appointed to the user. 
The following cases are not subject to penalty points:

- user does not use the system;

- user interrupts the process;

- used module or computer is turned on for any reason.

We denote the obtained points by $q_{j}$. The value of this parameter for each sub-module can be positive or negative, depending on the total penalty points:

$$
q_{j}=\sum_{i=1}^{m_{j}}\left(b_{j i}-c_{j i}\right) \text {. }
$$

The evaluation is formed through the comparison of the real user with the ideal user as follows:

Mean duration of stay at each sub-module and mean square tend required form the ideal user by the expert to study the specific information are given. In the case of absence of an expert evaluation, the values obtained by the formulas (4) and (5) for $t_{j i}^{\max }$ and $t_{j i}^{\min }$ can be taken.

1) We call the probability of providing the hypothesis, that the mean durations of stay in the system of both the ideal and real users are equal, by the user evaluation weight:

$$
\alpha_{j}=p\left(\frac{\left(\overline{\tau_{j}}-\overline{t_{j}}\right) \sqrt{m_{j}}}{\left(\sigma_{j}^{\tau}\right)^{2}+\left(\sigma_{j}\right)^{2}}\right) .
$$

2) The system evaluation is calculated as follows:

$$
q=\frac{\sum_{j=1}^{n} q_{j} \alpha_{j}}{\sum_{j=1}^{n} q_{j}^{\text {ideal }}}
$$

where

$$
q_{j}^{\text {ideal }}=\sum_{i=1}^{m_{j}} b_{j i}
$$

3) The evaluation results are determined with the use of Saaty's scale (Table 1) [11].

Table 1

Saaty's scale

\begin{tabular}{|c|c|}
\hline calculated value of $q$ & Evaluation results \\
\hline $0.80-1.00$ & Excellent - very good \\
\hline $0.63-0.80$ & good \\
\hline $0.37-0.63$ & satisfactory \\
\hline $0.20-0.37$ & unsatisfactory \\
\hline $0.00-0.20$ & bad \\
\hline
\end{tabular}




\section{Calculation experiment}

We assume that the user uses the information sources in 3modules and 3 sub-modules in each of them. The parameters of usage are provided in the Tables $2 \mathrm{a}$ and $2 \mathrm{~b}$.

Table $2 \mathrm{a}$

Parameters for using data sources

\begin{tabular}{|c|c|c|c|c|c|c|c|c|c|c|c|}
\hline \multirow{2}{*}{\begin{tabular}{|c}
$\begin{array}{c}\text { Sub- } \\
\text { module }\end{array}$ \\
1.1
\end{tabular}} & \multirow{2}{*}{$\begin{array}{c}\begin{array}{c}\text { Number } \\
\text { of } \\
\text { accesses }\end{array} \\
3.00\end{array}$} & \multicolumn{5}{|c|}{$\begin{array}{l}\text { Duration of } \\
\text { accesses }\end{array}$} & \multirow{2}{*}{\begin{tabular}{|c|}
$\begin{array}{c}\text { Mean } \\
\text { duration of } \\
\text { accesses }\end{array}$ \\
2.67 \\
\end{tabular}} & \multirow{2}{*}{$\begin{array}{c}\text { Mean square } \\
\text { tend of } \\
\text { duration of } \\
\text { accesses }\end{array}$} & \multirow{2}{*}{$\begin{array}{c}\begin{array}{c}\text { Expert } \\
\text { points } \\
t \pm \sigma\end{array} \\
2 \pm 0.5\end{array}$} & \multirow{2}{*}{\begin{tabular}{|c|}
$\begin{array}{c}\text { Total points } \\
\text { by sub- } \\
\text { modules }\end{array}$ \\
-1.00
\end{tabular}} & \multirow{2}{*}{$\begin{array}{c}\begin{array}{c}\text { Weighted } \\
\text { coefficients } \\
\text { by sub- } \\
\text { module }\end{array} \\
0.98\end{array}$} \\
\hline & & 2 & 3 & 3 & & & & & & & \\
\hline 1.2 & 5.00 & 3 & 5 & 4 & 6 & 3 & 4.20 & 1.30 & $3 \pm 0.5$ & 1.00 & 0.92 \\
\hline 1.3 & 4.00 & 4 & \begin{tabular}{l|l}
3 \\
\end{tabular} & 4 & 4 & & 3.75 & 0.50 & $3 \pm 0.5$ & -2.00 & 1.00 \\
\hline 2.1 & 2.00 & 3 & 3 & & & & 3.00 & 0.00 & $4 \pm 0.5$ & 2.00 & 1.00 \\
\hline 2.2 & 4.00 & 3 & 5 & 4 & 5 & & 4.25 & 0.96 & $3 \pm 0.5$ & 0.00 & 0.98 \\
\hline 2.3 & 3.00 & 4 & 4 & 3 & & & 3.67 & 0.58 & $2 \pm 0.5$ & 3.00 & 1.00 \\
\hline 3.1 & 6.00 & 3 & 4 & 3 & 6 & \begin{tabular}{l|l}
4 & 2
\end{tabular} & 4.00 & 1.10 & $3 \pm 0.5$ & 5.00 & 0.93 \\
\hline 3.2 & 5.00 & 5 & 4 & 4 & 3 & 3 & 3.80 & 0.84 & $3 \pm 0.5$ & 4.00 & 0.98 \\
\hline 3.3 & 4.00 & 3 & 3 & 4 & 3 & & 3.25 & 0.50 & $2 \pm 0.5$ & 4.00 & 1.00 \\
\hline & & & & & & & & 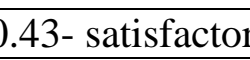 & & & \\
\hline
\end{tabular}

Table $2 b$

Parameters for using data sources

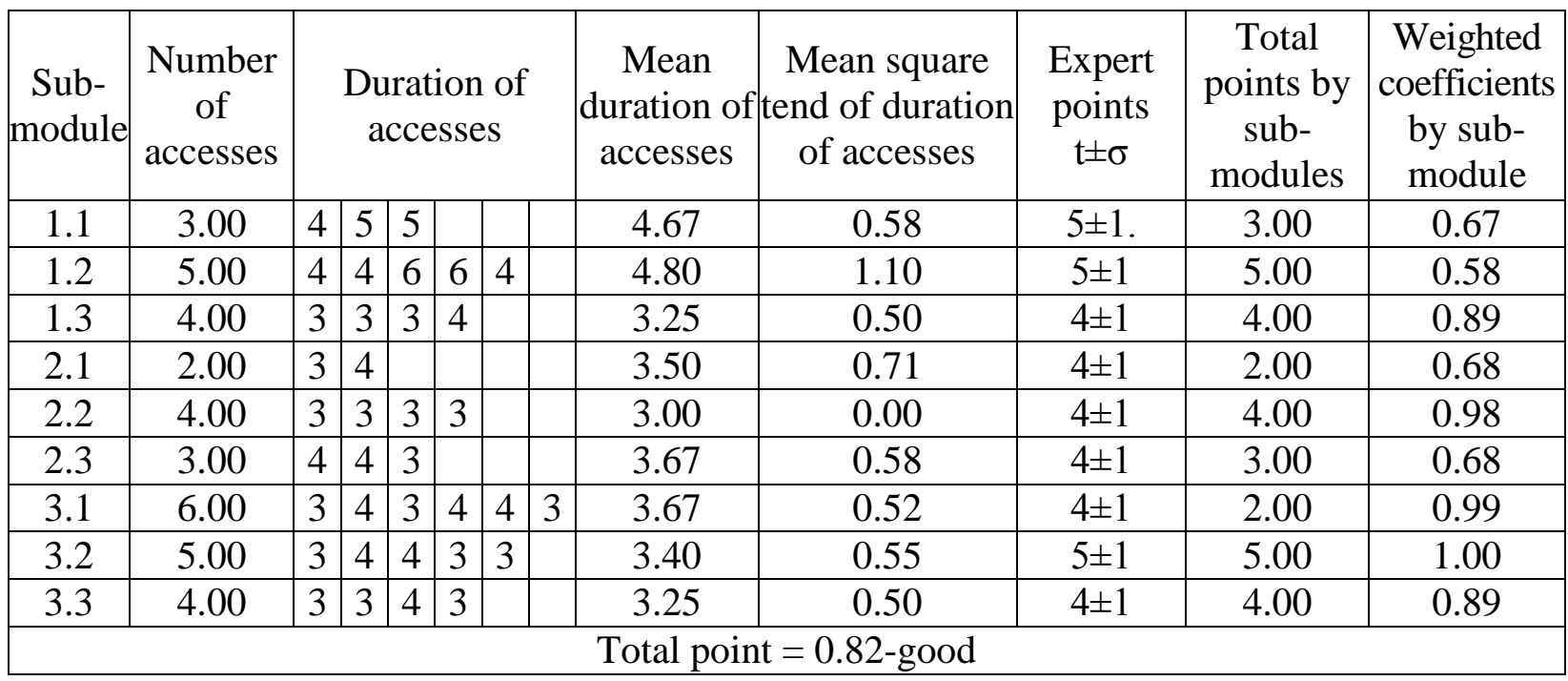

Table $2 \mathrm{a}$ and Table $2 \mathrm{~b}$ have been designed for the conditions, where the number of accesses to the program system is the same, but the durations of stay at the sub-modules differ. As it can be seen from the Table 2a, as the user's duration of stay at the sub-modules differs from the expert values, his/her activity has been assessed as satisfactory, whereas, in the second case (Table $2 \mathrm{~b}$ ), the user has performed different results in regards with the durations of stay at the 2nd submodule of the 3rd modules. 


\section{Conclusion and Suggestions}

1. The method for the evaluation of using the system in the virtual environment based on the statistical data has been presented.

2. The method can be used for the calculation of the rates of the various information resources, and for the initial assessment of the final examinations of the distance education learners, based on their preparation for the exams and colloquiums.

\section{References}

1. Guglielmo V. Virtual Revisions Classes Using a VLE/ International Conference on Cognition and Exploratory Learning in Digital Age (CELDA), 2005, pp.423-427.

2. Taylor P., Maor D. Assessing the efficacy of online teaching with the Constructivist On-Line Learning Environment Survey/ Proceedings of the 9th Annual Teaching Learning Forum. ctl.curtin.edu.au/events/conferences/tlf/tlf2000/taylor.html

3. Stiles M. J. Disability access to virtual learning environments. www.techdis.ac.uk/ index.php?p= 3_8_20051410041022

4. Rovai A., Ponton M., Baker J. Distance Learning in Higher Education. Columbia University Press, New York, 2009.

5. Chukhlomin V.D. Organization of distance learning in US higher education institutions // Economics and Organization of Industrial Production, 2007, No 10, pp.71-80.

6. Maguire M., Elton E., Osman Z., Nicolle C. Design of a virtual learning environment for students with special needs // An Interdisciplinary Journal on Humans in ICT Environments, 2006, vol.2 (1), pp.119-153. www.humantechnology.jyu.fi

7. Dyachenko A.V., Myaeots V.V., Popov A.E. Principles of building continuous education systems based on Internet technologies / Proceedings of the International scientific-practical conference "Information technologies in science and education", 2015, No12, pp.78-84.

8. Ostroukh A.V., Vasyugova S.A., Krasnyansky M.N., Samaratunga A. The study of the prospects and problems of human-computer integration: artificial intelligence, robotics, technological singularity and virtual reality // Prospects of Science, 2011, No 4 (19), pp.109-112.

9. Shuklin S.I. Optimization of virtual educational space in the professional training system based on competency approach // Yaroslavl Pedagogical Newspaper, 2009, No 4 (61), pp.88-91

10. Muller P., Noymann P., Shtorm R. Mathematical statistics tables, M.: Finance and Statistics, 1982, p.278.

11. Saaty T.L. Decisionmaking. The hierarchical analysis method, Moscow: Radio and Communication, 1989, p.316. 